\title{
Deathcore, creativity, and scientific thinking
}

\author{
David G Angeler $\ddagger$, Shana M Sundstrom§, Craig R Allenl
}

‡ Swedish University of Agricultural Sciences, Department of Aquatic Sciences and Assessment, Uppsala, Sweden $\S$ Nebraska Cooperative Fish and Wildlife Unit, School of Natural Resources, University of Nebraska - Lincoln, Lincoln, United States of America

I U.S. Geological Survey, Nebraska Cooperative Fish and Wildlife Unit, School of Natural Resources, University of Nebraska Lincoln, Lincoln, United States of America

\section{Abstract}

\section{Background}

Major scientific breakthroughs are generally the result of materializing creative ideas, the result of an inductive process that sometimes spontaneously and unexpectedly generates a link between thoughts and/or objects that did not exist before. Creativity is the cornerstone of scientific thinking, but scientists in academia are judged by metrics of quantification that often leave little room for creative thinking. In many scientific fields, reductionist approaches are rewarded and new ideas viewed skeptically. As a result, scientific inquiry is often confined to narrow but safe disciplinary ivory towers, effectively preventing profoundly creative explorations that could yield unexpected benefits.

\section{New information}

This paper argues how apparently unrelated fields specifically music and belief systems can be combined in a provocative allegory to provide novel perspectives regarding patterns in nature, thereby potentially inspiring innovation in the natural, social and other sciences. The merger between basic human tensions such as those embodied by religion and music, for example the heavy metal genre of deathcore, may be perceived as controversial, challenging, and uncomfortable. However, it is an example of moving the thinking process 
out of unconsciously established comfort zones, through the connection of apparently unrelated entities. We argue that music, as an auditory art form, has the potential to enlighten and boost creative thinking in science. Metal, as a fast evolving and diversifying extreme form of musical art, may be particularly suitable to trigger surprising associations in scientific inquiry. This may pave the way for dealing with questions about what we don't know that we don't know in a fast-changing planet.

\section{Keywords}

science, art, music, religion, creativity, inductivism, scientific process

\section{Overview and background}

It has become common practice in western societies to measure the performance of scientists using a combination of metrics related to academic productivity, publication prestige, and the acquisition of funding. Researchers usually respond to these demands by adopting a "save-to-play" strategy (i.e., sustained scientific output to maintain promotion and/or hiring options). Scholars are becoming increasingly aware of the risks that a generalized adoption of this strategy by scientists across disciplines, and independent of their career stages, can entail. This risk includes a bias towards, and emphasis on, deductive scientific processes while neglecting inductive approaches (Kahneman 2011), reduced risk-taking (especially regarding work outside the scientific mainstream, akin to Savage's sure-thing principle [Savage 1954]), and inquiry dominated by questions about what we know that we don't know (Logan 2009). The broader consequences are that not only scientists, but also scientific domains, are restricted to disciplinary ivory towers. To break this trend, calls have been made to boost creative thinking in science, and the arts are being recognized to play an important role in this process (Scheffer 2014).

The arts as an expression of creativity can play a crucial role in the scientific process. The arts can spur inductivism and stimulate and foster creative thinking. In turn, this can lead to "serendipitous" connections of isolated thoughts and ideas. Such creative mergers can reinforce critical thinking and open new and broader questions about what we don't know that we don't know of this complex world.

\section{Objectives}

Heavy metal music is a form of the auditory arts. We ask if and how it can be related to scientific creativity and thinking. We start by establishing a rationale that links metal with creative thinking in the sciences. We set the stage by invoking the challenges that not only scientists, but also humankind at large face in our current time of a swiftly changing planet. We present deathcore songs that exemplify mergers of apparently unrelated entities that 
become allegorical to environmental surprises in a highly uncertain, no-analogue future. We conclude by setting these allegories into a broader context of scientific inquiry

\section{Impact}

Ecological and social baselines on planet Earth are swiftly changing, driven by technological and industrial advances that result in novel and complex interactions between systems of people and nature (Berkes et al. 2002). Heavy metal music has shown a similarly rapid diversification and development with the emergence of multiple subgenres, leading to the establishment of a scientific field in its own right (Brown 2011). Many of the metal subgenres have systematically transgressed accepted boundaries in music as an art form (Kahn-Harris 2007), and metal is therefore rejected by many people. Paradoxically, metal can serve as a critical thinking model to help envision and prepare for emerging environmental problems. Many of these problems relate to current patterns of resource use, which humankind takes for granted but are unsustainable in the long term (Rockström et al. 2009). Heavy metal becomes a form of musical art that is allegorical to the observed broader changes in the biosphere. Given that many people reject heavy metal because of the negative feelings (aggression, noise, anxiety) the music causes, this musical genre may serve to symbolize similar feelings of discomfort people may experience in situations of environmental and humanitarian crisis.

Faced with a broad array of social-ecological challenges ranging from local to global scales, scientists are struggling with the high degree of uncertainty surrounding the future structure and function of ecosystems upon which human societies depend. Uncertainty means that there might emerge in the future novel forms of systems and interactions that we currently cannot envision. Surprise is an important factor in environmental change outcomes (Williams and Jackson 2007). Among these surprises are novel types of ecosystem with no-analogue systems and communities (combinations of plants and animals that are compositionally unlike any found today).

We propose that music and other artistic endeavors in general, and heavy metal in particular, has the potential to help scientists envision such surprises, thereby boosting their creativity and critical thinking. We show this through the merger of sound elements from different instruments. These combinations allow for subjective associations between apparently unrelated entities to be made. The resulting emergent song structure creates a surprising complexity that is allegorical to a potential no-analogue outcome of environmental change in the future. We show this potential using song examples from deathcore. Songs from the plethora of other metal subgenres, or other music genres, are equally suitable, and will hopefully serve as a basis for a similar line of inquiry presented in this paper.

Deathcore is an extreme metal fusion genre that combines the characteristics of metalcore and death metal, and occasionally hardcore punk. Deathcore is typified by down-tuned guitars, tremolo picking, melodic riffs, fast drumming (including blast beats), growled and/or screamed vocals, and typical metalcore breakdowns. A number of deathcore bands include 
synthesizers in addition to guitars, drums, and vocals in their song architecture (e.g., Born of Osiris, Betraying the Martyrs, Make Them Suffer, etc.). The amalgamation of different sounds and instruments in deathcore creates associations in the listener that become the source for creative thinking. Although associations are inherently subjective, and their interpretation may therefore vary between persons, we show how such subjective interpretation can boost creativity by creating a link between apparently unconnected entities, ideas or thoughts.

In some deathcore songs, the synthesizers introduce elements that can be associated with many visions of heaven, based on their sound structure. Heaven plays a central part in religion and cosmology. Gods, angels, saints, or venerated ancestors are said to originate, be enthorned, or live in heaven (https://en.wikipedia.org/wiki/Heaven). In contrast, the guitars, drumming, and vocals account for the aggresiveness and brutality that is inherent in this musical genre. These components of song architecture can be associated with hell, a place of torment and punishment in an afterlife in many mythological, folklore and religious traditions. Hell can be ruled by a dead god or the Devil, and the demons that populate hell are often portrayed to torment those dwelling there (https:/en.wikipedia.org/ wiki/Hell). In fact, this interpretation is reflected practically in applications of metal in psychological operations, i.e. during interrogations of detainees (BBC 2003).

The interaction of these metaphorical elements (heaven, hell; good, evil) results in an emergent song structure that becomes allegorical to "whispers between heaven and hell". In turn, this symbolic conversation between realms, united in deathcore songs, becomes an allegory to the axis mundi, or world tree, another belief model in religion that connects the heavens, the terrestrial world, and the underworld. In a sustainability context, this axis mundi might be associated with a representation of the connector of interacting entities (e.g. assemblages of plants and animals), the glue that makes novel ecosystems viable in the future.

Our ideas and associations have been inspired by the song "The Better Half of Me" that appears on the recent release, Souls Sphere, of the American deathcore band Born of Osiris. There is a ca. 10-sec long passage at 0:39, following the domination of rhythmic complexity led by screaming vocals, drumming, and guitars, when the synthesizers give a metaphorical shy celestial whisper to hell. These whispers culminate in an intense period at 1:28 and another at 2:27 when the synthesizers give heaven the upper hand while hell provides harmonic agreement to this symbolic musical conversation.

There are other examples showcasing such allegorical whispers. Examples from a range of bands can be found at: https://www.youtube.com/watch? $v=j j 2 X B S s q l t E$. These examples allow for further associations between deathcore song architecture and phenomena in nature. For example, scaling is a central idea in ecology. It focuses on the spatial and temporal scales at which certain patterns and processes can occur (Allen et al. 2014). For instance, the reproduction of an annual grass in a small field $v s$. a landslide vs. continental drifts structuring the earth's surface represent processes that unfold at very distinct scales of time and space. Some deathcore songs (e.g., Engulfed by Sun [Assemble the Chariots]) show similar scaling in their architecture. That is, the synthesizers play sustained and 
prolonged accords while the drumming, guitars, and vocals have a fast, rhythmic recurrence. The resulting song structure becomes a multi-scaled and dynamic manifestation of the symbolic axis mundi, or more practically, a metal allegory of the patterns and processes that shape systems of people and nature.

\section{Implementation}

In this paper we have combined heavy metal music with religion, cosmology and folklore. Mergers between basic human tensions (such as those embodied by religion or ying and yang) and a fringe musical genre, like metal, may be perceived as strange, provocative and irritating. Indeed, the world has witnessed the sad culmination of such negative associations with religion during the recent terror attacks in Paris, which included a metal concert as target. Our paper must be solely understood as an example to showcase how creativity can boost inductive and associative thinking to establish a link between apparently unrelated ideas, thoughts or objects. Ultimately, our aim is to show how the entire creative process should be pushed out of established comfort zones, something that art and music has consistently accomplished, but which is poorly developed, and not rewarded, in science. By definition, humans tend to create a psychological state in which a person experiences low anxiety and stress because they feel comfortable, at ease, and in control, which facilitates a steady level of performance (White 2009). Scientists are humans, and therefore may unconsciously construct a comfort zone of hypotheticaldeductive inference.

Both, the auditory and visual arts can serve as a great inspiration to scientists (Scheffer et al. 2015). In fact, the painting "Whisper between Heaven and Hell" by the American artist and photographer Bob Orsillo's; http://fineartamerica.com/featured/whisper-betweenheaven-and-hell-bob-orsillo.html) provides a visual underpinning of our ideas presented in this paper. Exploration without limits is the raison d'être of our sciences. There is much uncharted territory for exploring how isolated, unrelated or antithetical entities in systems, like heaven and hell united in deathcore, can be connected and dynamic interactions between those identified. Continuing this or similar lines of explorations may help us, the scientists, grasp some of the seemingly intractable complexity of our world. In turn, this may pave the way for dealing with questions about what we don't that know we don't know in a fast-changing world and ultimately help mankind to cope with and adjust to a transforming planet.

\section{Acknowledgements}

This paper is an extended version of the post Whispers between heaven and hell: Scientists listen up! that has been published on the lead author's blog ( https:// artsciencesite.wordpress.com/). This study was partly financed by the August T. Larsson foundation (NJ Faculty, Swedish University of Agricultural Sciences). 


\section{Author contributions}

David Angeler conceived this study and has written the manuscript. Shana Sundstrom and Craig Allen contributed to idea development and the writing.

\section{Conflicts of interest}

The authors declare no conflict of interests.

\section{References}

- $\quad$ Allen CR, Angeler DG, Garmestani AS, Gunderson LH, Holling CS (2014) Panarchy: Theory and applications. Ecosystems 17: 578-589. DOI: 10.1007/s10021-013-9744-2

- $\quad$ BBC (2003) Sesame Street breaks Iraqi POWs. http://news.bbc.co.uk/go/pr/fr/-/2/hi/ middle east/3042907.stm. Accession date: 20151114.

- Berkes F, Colding J, Folke C (2002) Navigating Social-Ecological Systems. Cambridge University Press, 393 pp. URL: http://dx.doi.org/10.1017/cbo9780511541957 DOI: 10.1 017/cbo9780511541957

- $\quad$ Brown A (2011) Heavy Genealogy: Mapping the Currents, Contraflows and Conflicts of the Emergent Field of Metal Studies, 1978-2010. Journal for Cultural Research 15 (3): 213-242. DOI: 10.1080/14797585.2011.594579

- Kahneman D (2011) Thinking, Fast and Slow. Farrar, Straus and Hiroux, 512 pp.

- Kahn-Harris K (2007) Extreme Metal: Music and Culture on the Edge. Berg, 224 pp.

- Logan DC (2009) Known knowns, known unknowns, unknown unknowns and the propagation of scientific enquiry. Journal of Experimental Botany 60 (3): 712-714. DOI: 10.1093/jxb/erp043

- Rockström J, Steffen W, Noone K, Persson Å, Chapin FS, et al (2009) Planetary boundaries: exploring the safe operating space for humanity. Ecology and Society 14 : 32.

- $\quad$ Savage LJ (1954) The foundations of statistics. Wiley and Sons, $310 \mathrm{pp}$.

- Scheffer M (2014) The forgotten half of scientific thinking. Proceedings of the National Academy of Sciences 111 (17): 6119-6119. DOI: 10.1073/pnas.1404649111

- Scheffer M, Bascompte J, Bjordam T, Carpenter S, Clarke L, Folke C, Marquet P, Mazzeo N, Meerhoff M, Sala O, Westley F (2015) Dual thinking for scientists. Ecology and Society 20 (2): 3. DOI: 10.5751/es-07434-200203

- White A (2009) From Comfort Zone to Performance Management. White \& MacLean Publishing, $20 \mathrm{pp}$.

- Williams J, Jackson S (2007) Novel climates, no-analog communities, and ecological surprises. Frontiers in Ecology and the Environment 5 (9): 475-482.

DOI: $10.1890 / 070037$ 